\title{
Potentiometric determination of moxifloxacin in some pharmaceutical formulation using PVC membrane sensors
}

\author{
Mohammed M Hefnawy ${ }^{1}$, Atef M Homoda ${ }^{2}$, Mohammed A Abounassif ${ }^{1}$, Amer M Alanazi ${ }^{1}$, \\ Abdulrahaman Al-Majed ${ }^{1}$ and Gamal A Mostafa ${ }^{1 *}$
}

\begin{abstract}
Background: The construction and electrochemical response characteristics of Poly (vinyl chloride) membrane sensors for moxifloxacin $\mathrm{HCl}(\mathrm{MOX})$ are described. The sensing membranes incorporate ion association complexes of moxifloxacin cation and sodium tetraphenyl borate (NaTPB) (sensor 1), phosphomolybdic acid (PMA) (sensor 2) or phosphotungstic acid (PTA) (sensor 3) as electroactive materials.

Results: The sensors display a fast, stable and near-Nernstian response over a relative wide moxifloxacin concentration range $\left(1 \times 10^{-2}-4.0 \times 10^{-6}, 1 \times 10^{-2}-5.0 \times 10^{-6}, 1 \times 10^{-2}-5.0 \times 10^{-6} \mathrm{M}\right)$, with detection limits of $3 \times 10^{-6}, 4 \times 10^{-6}$ and $4.0 \times 10^{-6} \mathrm{M}$ for sensor 1,2 and 3, respectively over a pH range of $6.0-9.0$. The sensors show good discrimination of moxifloxacin from several inorganic and organic compounds. The direct determination of $400 \mu \mathrm{g} / \mathrm{ml}$ of moxifloxacin show an average recovery of $98.5,99.1$ and $98.6 \%$ and a mean relative standard deviation of 1.8, 1.6 and 1.8\% for sensors 1,2 and 3 respectively.

Conclusions: The proposed sensors have been applied for direct determination of moxifloxacin in some pharmaceutical preparations. The results obtained by determination of moxifloxacin in tablets using the proposed sensors are comparable favorably with those obtained using the US Pharmacopeia method. The sensors have been used as indicator electrodes for potentiometric titration of moxifloxacin.
\end{abstract}

Keywords: Moxifloxacin HCl, Sodium tetraphenyl borate, Phosphomolybdic acid, Phosphotungstic acid, PVC, Potentiometry

\section{Background}

Moxifloxacin (MOX) (1-cyclopropyl-6-fluoro-1,4- dihydro8-methoxy-7-[(4aS,7aS)-octahydro-6H-pyrrolo [3,4-b]pyridin-6-yl]4-oxo-3 quinoline carboxylic acid) (Figure 1) is an advanced-generation, 8-methoxyquinolone derivate of fluoroquinolone antibacterial agent that is synthetic. It was discovered in 1999 [1,2]. Moxifloxacin is a broad-spectrum antibiotic that is active against both Gram-positive and Gram-negative bacteria. It functions by inhibiting DNA gyrase, a type II topoisomerases, and topoisomerase IV [3], enzymes necessary to separate bacterial DNA, thereby inhibiting cell replication.

\footnotetext{
* Correspondence: gamal_most@yahoo.com

${ }^{1}$ Pharmaceutical Chemistry Department, College of Pharmacy, King Saud University, P.O.Box 2457, Riyadh 11451, Saudi Arabia

Full list of author information is available at the end of the article
}

Various methods cited in literature for its determinations involve, spectrophotometry [4,5], spectrofluorimetry [6], atomic absorption spectrometry [7], conductometry [7], voltammetry [8], high performance liquid chromatographyultraviolet (HPLC-UV) [9-11], HPLC-fluorescence (HPLCFl) [12-14] capillary electrophoresis (CE) $[15,16]$, and HPLC-mass spectrometry (HPLC-MS) $[17,18]$. However, most of these methods involve time-consuming procedures, derivatization and/ or sophisticated instruments.

Due to the fact that MOX is a compound of great pharmacological and analytical importance, in recent years, there has been an increased interest to develop accurate analytical methods which are valid for quantification of MOX in biological and pharmaceutical samples.

Potentiometric methods, using ion selective electrodes, have found wide application [19-21] being simple, eco- 


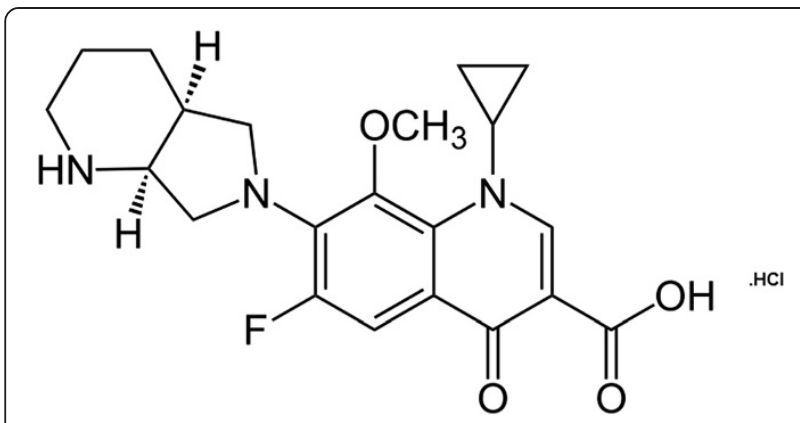

Figure 1 Chemical structure of moxifloxacin hydrochloride.

nomical, applicable over a wide range of different areas, with applicability to turbid and colored solutions, and offering enough selectivity towards the drug in the presence of various pharmaceutical excipients. To the best of our knowledge till now no potentiometric membrane sensors for MOX have been published. The proposed sensors are based on the use of PVC membrane sensor of MOX - tetraphenylborate or MOX-phosphomolybdate or MOX-phosphotungstate as electroactive materials. The present work describes the construction and evaluation of novel PVC electrochemical sensors for the sensitive and selective determination of moxifloxacin in its pharmaceutical preparations.

\section{Experimental \\ Apparatus}

All potentiometric measurements were made at $25 \pm 1^{\circ} \mathrm{C}$ unless otherwise stated using an Orion $\mathrm{pH} / \mathrm{mV}$ meter (model 330) using MOX membrane sensors in conjunction with an Orion double junction $\mathrm{Ag} / \mathrm{AgCl}$ reference electrode (model $90-02)$ containing $10 \%(\mathrm{w} / \mathrm{v})$ potassium nitrate in the outer compartment. Adjustment of $\mathrm{pH}$ was made with a combined Ross glass $\mathrm{pH}$ electrode (Orion 81-02) for all $\mathrm{pH}$ measurements.

\section{Reagents and materials}

All chemicals used were of analytical reagent grade unless otherwise stated and doubly distilled water was used throughout. Polyvinyl chloride powder (PVC) high molecular weight, dibutyl sebacate (DBS), dioctyl phthalate (DOP), o-nitrophenyl octylether (NPOE), tetrahydrofurane (THF) of purity $>99 \%$ were obtained from Aldrich Chemical Company and MOX was obtained from Sigma Chemical Company, Germany. Sodium tetraphenylborate (NaTPB), phosphomolybdic acid (PMA) and phosphotungstic acid (PTA), were obtained from BDH, Chemical Ltd. Avelox $400 \mathrm{mg}$, Manufactured by Bayer was obtained from local pharmacy. The stock solution of $1 \times 10^{-2} \mathrm{M} \mathrm{MOX} \mathrm{was}$ prepared by dissolving the appropriate amount of MOX in $100 \mathrm{ml}$ of water. Five standard MOX solutions were prepared in the range of $1 \times 10^{-2}-1 \times 10^{-6} \mathrm{M}$ by diluting the appreciate amount in double distilled water. Tris buffer of $\mathrm{pH} 7.0$ was prepared by mixing $100 \mathrm{ml}$ of $0.1 \mathrm{M}$ tris(hydroxymethyl) aminomethane hydrochloride, with appropriate $0.1 \mathrm{M} \mathrm{HCl}$.

\section{Preparation of the MOX-PVC membrane sensors}

Upon the addition of $25 \mathrm{ml}$ of $1 \times 10^{-2} \mathrm{M}$ of MOX solution to $25 \mathrm{ml}$ each of $1 \times 10^{-2} \mathrm{M}$ sodium tetraphenyl borate or $75 \mathrm{ml}$ of $1 \times 10^{-2} \mathrm{M}$ of MOX solution to $25 \mathrm{ml}$ phosphotungstic acid respectively, a whitish precipitate of MOX-TPB or yellowish precipitate of MOX-PA or MOXPT were formed, respectively. The precipitate was filtered off through a Whatman filter paper No. 42, washed with cold deionized water until no chloride ion was detected into the washing solution. The precipitate was dried under vacuum for $48 \mathrm{~h}$, then grinded to a fine powder in mortar, forming ion-pairs complex. The elemental analysis confirmed the formation of 1:1 or 3:1 complex of MOX:TPB or MOX:PM or MOX:PT, respectively. Portion of ten mg of the prepared ion associate complexes were thoroughly mixed with $190 \mathrm{mg}$ PVC powder, $350 \mathrm{mg}$ of DBS or DOP or NPOE and $5 \mathrm{ml}$ THF in glass Petri dishes $(5 \mathrm{~cm}$ diameter). After the constituents being well mixed, the solvent has been allowed to evaporate overnight while the sensing membranes have been formed. The PVC master membranes were sectioned with a cork borer $(10 \mathrm{~mm}$ diameter) and glued to a polyethylene tube $(3 \mathrm{~cm}$ length, $8 \mathrm{~mm}$ I.D.) using THF [22,23]. Laboratory made electrode bodies were used, which consisted of a glass tube, to which the polyethylene tube is attached at one end and filled with internal reference solution (equal volumes of $1 \times 10^{-2} \mathrm{M}$ aqueous solution of MOX and $\mathrm{KCl}$ ). $\mathrm{Ag} / \mathrm{AgCl}$ internal reference electrode (1.0 mm diameters) was used. The indicator electrode was conditioned by soaking in a $1 \times 10^{-2} \mathrm{M}$ aqueous MOX solution for $1 \mathrm{~h}$ and stored in the same solution when not in use.

\section{Procedure}

The moxifloxacin PVC membrane sensors were calibrated by immersion in conjunction with the reference electrode in a $50 \mathrm{ml}$ beaker containing $9.0 \mathrm{ml}$ of tris-buffer of $\mathrm{pH}$ 7.0. Then $1.0 \mathrm{ml}$ aliquot of MOX solution was added with continuous stirring, to give final MOX concentration ranging from $1 \times 10^{-2}$ to $1 \times 10^{-6} \mathrm{M}$ and the potential was recorded after stabilization to $\pm 0.5 \mathrm{mV}$. A calibration curves were constructed by plotting the recorded potentials as a function of $-\log [\mathrm{MOX}]$. The resulting graphs were used for subsequent determination of unknown moxifloxacin concentration.

\section{Determination of moxifloxacin in the pharmaceutical dosage forms}

Ten tablets of Avelox $400 \mathrm{mg}$ were accurately weighed, crushed, mixed in a mortar. An appropriate amount 
(400 mg of moxifloxacin powder, from each) was weighed, transferred to a $100 \mathrm{ml}$ beaker and dissolved in double distilled water, sonication for about $15 \mathrm{~min}$ and completed to the mark with the water. A $5.0 \mathrm{ml}$ aliquots of these solutions were transferred to $50 \mathrm{ml}$ standard flask, the $\mathrm{pH}$ was adjusted to 7.0 using tris buffer and completed to the mark with water. The potential of the solution was measured using MOX-sensors in conjunction with an Orion $\mathrm{Ag} / \mathrm{AgCl}$ double junction reference electrode. The potential of the stirred solution was recorded after the signal stabilization $( \pm 0.5 \mathrm{mV} / \mathrm{min})$ and the concentration was calculated from the previous calibration graph under identical experimental conditions from standard solutions of MOX.

Alternatively, the potentials displayed by moxifloxacin test solution before and after the addition of a $1.0 \mathrm{ml}$ aliquot of $1 \times 10^{-3} \mathrm{M}$ moxifloxacin were measured. The change in the potential readings was recorded and used to calculate the unknown moxifloxacin concentration in the test solution using the standard addition technique [24].

Reconstituted powder: one mixture was prepared with a known amount of moxifloxacin powdered $(20 \mathrm{mg})$ and other components such as starch, lactose and magnesium stearate. The accuracy of the potentiometric determination of MOX in this powdered was checked by evaluation the recovery.

\section{Results and discussion}

Sodium tetraphenyl borate, phosphomolybdic acid, and phosphotungstic acid were tested as ion-pairing agent for the preparation of electroactive ion association complexes for MOX. Sparingly soluble complexes of MOX-TPB, MOX- PM or MOX - PT have been instantaneously formed upon the addition of MOX solution to solutions of Na TPB, PMA or PTA respectively. The dry powder of the formed ion pairs are used for the construction of a new moxifloxacin ion selective electrodes. The elemental analysis showed that the composition of the complex is 1:1 in case of MOX:TPB, 3:1 for MOX: PM or MOX-PT respectively. Plasticized polymeric membranes were prepared by using membrane cocktails with compositions $1.82 \%$ of the corresponding ionic pair (MOX-TPB or MOX-PM or MOX-PTA), 34.54\% of PVC and $63.64 \%$ of the corresponding plasticizer (DBS, DOP and NPOE).

\section{Effect of plasticizer type on the characteristic performance of the sensors}

Moxifloxacin ion-selective membrane sensors with different electroactive materials were investigated in order to compare their performance. Three reagents were investigated as possible counter ion for the preparation of the electroactive complex of MOX, namely TPB or PM or PTA were tested as ion-pair reagents. The obtained ion-pairs combined with three plasticizer, DOP, DBS and NPOE to give different combinations were tested. It is well known that the construction of PVC based ISEs required the use of a plasticizer which acts as a fluidizer allowing homogenous dissolution and diffusion mobility of the ion-pair inside the membrane. PVC membrane sensor of MOX-TPB, MOX-PM or MOX-PT with different plasticizer namely (DBS or DOP or NPOE) was found to be all suitable and optimum available mediators for MOX membrane sensors. In fact, o-NPOE was found to be the optimum available mediator for MOX-TPB, MOX-PM or MOX-PT membrane sensors (ion-associates). The use of non polar mediators such as DBS, DOP gave less solubility of the ion-pair and less response of the analyte compared with o-NPOE.(slope about $50.0 \mathrm{mV}$ per concentration decade for both DBS and DOP respectively). It seems that o-NPOE improves the membrane selectivity due to its high dialectical constant $(\varepsilon=24)$, affects considerable dissolution of ion-association within the membrane; consequently enhances its partition coefficient in the membrane and also provided suitable mechanical property of the membrane compared with less permittivity plasticizers of DBS $(\varepsilon=4)$ or DOP $(\varepsilon=7)$ and the solubility of electroactive materials are relatively small compared with NPOE. Ortho-nitrophenyl octylether was used in case of MOX-TPB, MOX-PM or MOX-PT for carrying out other experiments in this investigation.

\section{Effect of $\mathrm{pH}$ and the response time}

The electrode response for different moxifloxacin concentrations was tested at different $\mathrm{pH}$ values, the $\mathrm{pH}$ being adjusted using hydrochloric acid or sodium hydroxide. The MOX-PVC electrode dipped into MOX solution of $1 \times 10^{-3}$ and $1 \times 10^{-4} \mathrm{M}$ the potential of the electrode was plotted against the $\mathrm{pH}$ of solution. The potentials show that the slope per concentration decade is constant $(\sim 53.0 \pm 0.5$ or $54.5 \pm 0.5$ or $55.0 \pm 0.5 \mathrm{mV}$ for MOX $-\mathrm{PM}$ or MOX -PT respectively) in the $\mathrm{pH}$ range of 6-9.0 (Figure 2). At higher $\mathrm{pH}$ values ( $>9.5$ ), the potential decreased due to the gradual increase in the concentration of the unprotonated MOX.

Average response time is defined [25] as the time required for the electrode to reach a stable potential within $\pm 1 \mathrm{mV}$ of the final equilibrium value. After successive immersion of the electrode in different moxifloxacin solutions each having a 10-fold difference in concentration or after rapid 10-fold increase in concentration by addition of MOX. The response time was found to be 20s for concentration of $\geq 1 \times 10^{-3} \mathrm{M}$ and $\leq 30 \mathrm{~s}$ for concentration $1 \times 10^{-4} \mathrm{M}$. Day-to-day reproducibility of the sensor is about $\pm 0.5 \mathrm{mV}$ for the same solution and the useful lifetime of the sensor is 4 weeks, during which the potential slope is reproducible to within $\pm 1 \mathrm{mV} /$ decade. Also after more than one month a new section from the master membrane was found to work with a good reproducibility. 


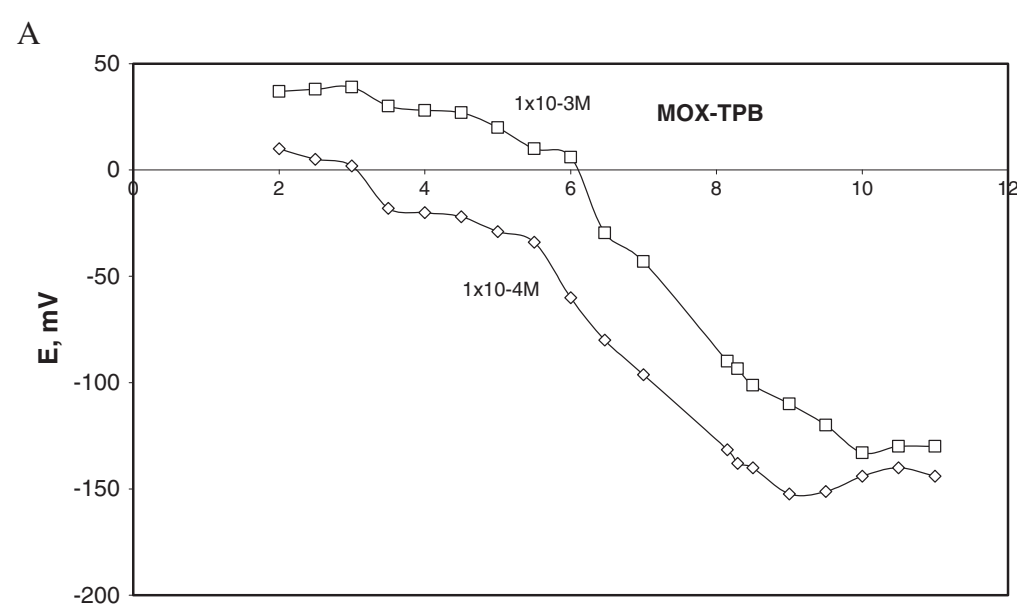

B

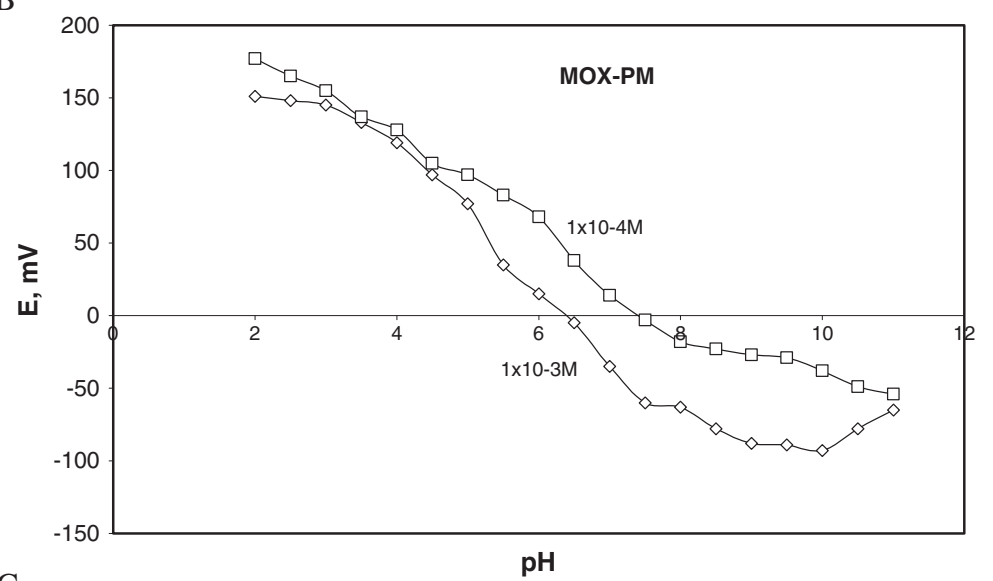

$\mathrm{C}$

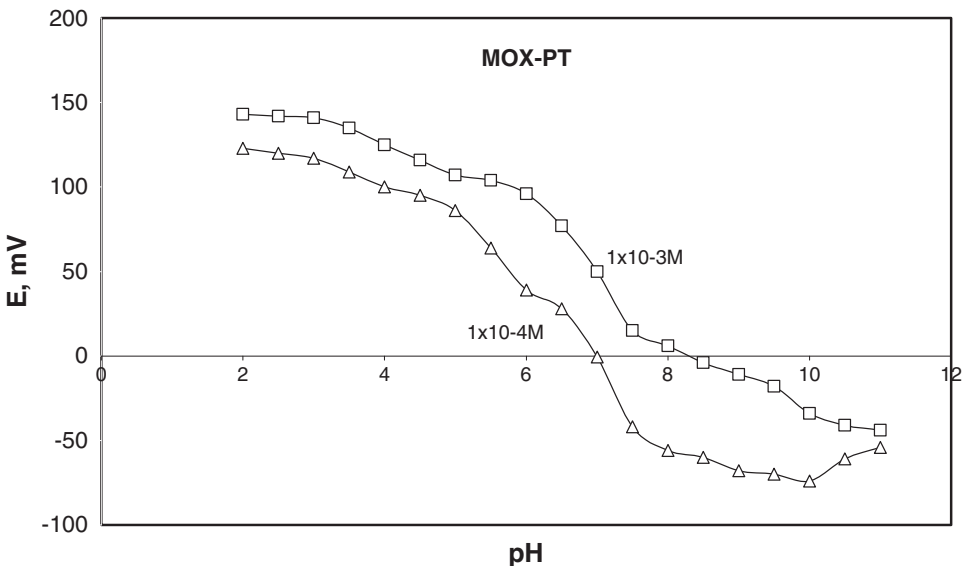

Figure 2 Effect of $\mathrm{pH}$ on the response of moxifloxacin sensors A) MOX-TPB, B) MOX-PM and C) MOX-PT using two series of moxifloxacin solutions: $1 \times 10^{-3} \mathrm{M}$, and $1 \times 10^{-4} \mathrm{M}$.

\section{Effect of diverse ions}

The influences of different organic and inorganic ions on the response of MOX sensors were investigated. The selectivity coefficients $K_{M F, B}^{P o t}$ were evaluated according to IUPAC guidelines using the separate solution method (SSM) or mixed solution method $[25,26]$ in tris-buffer solution of $\mathrm{pH} 7.0$. The selectivity coefficient $K_{M O X, B}^{\text {pot }}$ measured by separate solution method was calculated from the following equation:

$$
\log K_{A, B}^{p o t}=E_{B}-E_{A} / S+\left[1-Z_{A} / Z_{B}\right] \log a_{A}
$$


where $E_{A}$ and $E_{B}$ are the potential reading observed after $1 \mathrm{~min}$ of exposing the sensor to the same concentration of MOX and interfering species $\left(1 \times 10^{-3}\right.$ each) alternatively. The symbol $\mathrm{a}_{\mathrm{A}}$, and $\mathrm{a}_{\mathrm{B}}$ are the activity of MOX and interfering species and $Z_{A}$ and $Z_{B}$ are the charge of moxifloxacin and interfering species and $S$ is slope of calibration graph $(\mathrm{mV} /$ concentration). The selectivity coefficient by mixed solution method was defined as the activity ratio of primary and interfering ions that give the same potential change under identical conditions as given in equation 3 .

$$
K_{A, B}^{p o t}=\left(a_{A}^{\prime}-a_{A}\right) / a_{B}
$$

Where ${ }^{\prime}{ }_{A}$ known activity of primary ion solution added into a reference solution that contains a fixed activity $\left(a_{A}\right)$ of primary ions, and the corresponding potential change $(\Delta \mathrm{E})$ is recorded. Next, a solution of an interfering ion $\left(\mathrm{a}_{\mathrm{B}}\right)$ is added to the reference solution until the same potential change $(\Delta \mathrm{E})$ is recorded. The change in potential produced at the constant back ground of the primary ion must be the same in both cases. The results are given in Table 1. The results reveal reasonable selectivity for MOX in presence of many related substances.

\section{Sensors characteristics}

The potentiometric response characteristics of the moxifloxacin sensors based on the use of MOX-TPB, MOXPM or MOX-PT ion pair complexes and DBS or DOP or NPOE as a plasticizer in a PVC matrixes were evaluated according to IUPAC recommendations [25]. Results in Table 2 show the characteristics performance of the PVC membrane sensors. The least squares equations obtained from the calibration data as follows:

Table 1 Potentiometric selectivity coefficients of some interfering ions, using MOX

\begin{tabular}{|c|c|c|c|}
\hline Interferent, J & $\begin{array}{l}K_{M F, \text { Bot }}^{\text {Bo }} \\
\text { MOX-TPB }\end{array}$ & $\begin{array}{l}K_{M F, B}^{P o t}, \\
\text { MOX-PM }\end{array}$ & $\begin{array}{l}K_{M F, B}^{\text {Pot }} \\
\text { MOX-PT }\end{array}$ \\
\hline $\mathrm{Na}^{+\mathrm{a}}$ & $1.3 \times 10^{-3}$ & $1.3 \times 10^{-3}$ & $1.65 \times 10^{-3}$ \\
\hline $\mathrm{K}^{+\mathbf{a}}$ & $2.9 \times 10^{-3}$ & $3.33 \times 10^{-3}$ & $1.2 \times 10^{-4}$ \\
\hline $\mathrm{Ca}^{2+\mathrm{a}}$ & $1.5 \times 10^{-3}$ & $1.49 \times 10^{-3}$ & $1.79 \times 10^{-3}$ \\
\hline $\mathrm{Cu}^{2+\mathrm{a}}$ & $1.84 \times 10^{-3}$ & $1.845 \times 10^{-3}$ & $2.4 \times 10^{-2}$ \\
\hline $\mathrm{Co}^{2+\mathrm{a}}$ & $9.5 \times 10^{-3}$ & $9.5 \times 10^{-3}$ & 0.0113 \\
\hline $\mathrm{Mg}^{2+\mathrm{a}}$ & $9.1 \times 10^{-3}$ & $1.55 \times 10^{-3}$ & $1.65 \times 10^{-2}$ \\
\hline Magnesium stearate $^{\mathbf{b}}$ & $2.0 \times 10^{-3}$ & $2.18 \times 10^{-3}$ & $2.4 \times 10^{-3}$ \\
\hline Glucose $^{b}$ & $2.0 \times 10^{-3}$ & $2.09 \times 10^{-3}$ & $2.4 \times 10^{-3}$ \\
\hline Lactose monohydrate $^{\mathbf{b}}$ & $2.0 \times 10^{-3}$ & $2.27 \times 10^{-3}$ & $2.51 \times 10^{-3}$ \\
\hline Starch $^{\mathbf{b}}$ & $2.0 \times 10^{-3}$ & $2.27 \times 10^{-3}$ & $1.79 \times 10^{-3}$ \\
\hline Microcrystalline cellulose $^{b}$ & $2.0 \times 10^{-3}$ & $2.27 \times 10^{-3}$ & $1.79 \times 10^{-3}$ \\
\hline
\end{tabular}

${ }^{a}$ separate solution method and ${ }^{b}$ mixed solution method.
Table 2 Response characteristics of moxifloxacin-PVC matrix membrane sensors

\begin{tabular}{|c|c|c|c|}
\hline Parameter & MOX-TPB & MOX-PM & MOX-PT \\
\hline Slope, (mV/ decade) & $53.0 \pm 0.5$ & $54.5 \pm 0.5$ & $55.0 \pm 0.5$ \\
\hline Intercept, mV & $137.8 \pm 0.5$ & $143.03 \pm 0.5$ & $141.78 \pm 0.5$ \\
\hline Correlation coefficient, $(r)$ & 0.996 & 0.995 & 0.995 \\
\hline $\begin{array}{l}\text { Lower limit of detection } \\
\text { (LOD), } M\end{array}$ & $4.0 \times 10^{-6}$ & $5 \times 10^{-6}$ & $5 \times 10^{-6}$ \\
\hline $\begin{array}{l}\text { Lower limit of quantification } \\
\text { (LOQ), M }\end{array}$ & $3.0 \times 10^{-6}$ & $4.0 \times 10^{-6}$ & $4.0 \times 10^{-6}$ \\
\hline $\begin{array}{l}\text { Response time for } \\
1 \times 10^{-3} \mathrm{M} \text { solution, } \mathrm{s}\end{array}$ & $30 \pm 0.5$ & $30 \pm 0.5$ & $30 \pm 0.5$ \\
\hline Working $\mathrm{pH}$ range & $6.0-9.0$ & $6.0-9.0$ & $6.0-9.0$ \\
\hline
\end{tabular}

$$
E(m V)=\operatorname{Slog}[M O X]+\text { Intercept }
$$

where $E$, is the potential of the electrode, $S$ equal slope of the electrodes $(53.0 \pm 0.5,54.5 \pm 0.5$ and $55.5 \pm 0.5 \mathrm{mV}$ for MOX-TPB, MOX-PM, and MOX-PT, respectively) and intercept $(137.8 \pm 0.5,143.04 \pm 0.5$ and $141.78 \pm 0.5$ for MOX-TPB, MOX -PM, and MOX -PT, respectively).

\section{Validity of the proposed method}

\section{Limit of quantification and limit of detection}

Each of different concentration of standard solution was tested five times. The potentials obtained for the five analyses were averaged at each concentration. The average potential was plotted versus concentration. The relation between potential and concentration is logarithmic (equation 1) $X=S \log [\mathrm{MOX}]+Y$, where $X$ is equal the potential, $S$ is the slope, and $Y$ is the intercept and $(r)$ is the correlation coefficient. The sensors display a linear response over the concentration range $1 \times 10^{-2}$ to $4 \times 10^{-6}$, $1 \times 10^{-2}$ to $5.0 \times 10^{-6}, 1 \times 10^{-2}$ to $5.0 \times 10^{-6} \mathrm{M}$ ), respectively over a $\mathrm{pH}$ range of $6.0-9.0$. The limits of detection (LOD) and limits of quantification (LOQ) were determined

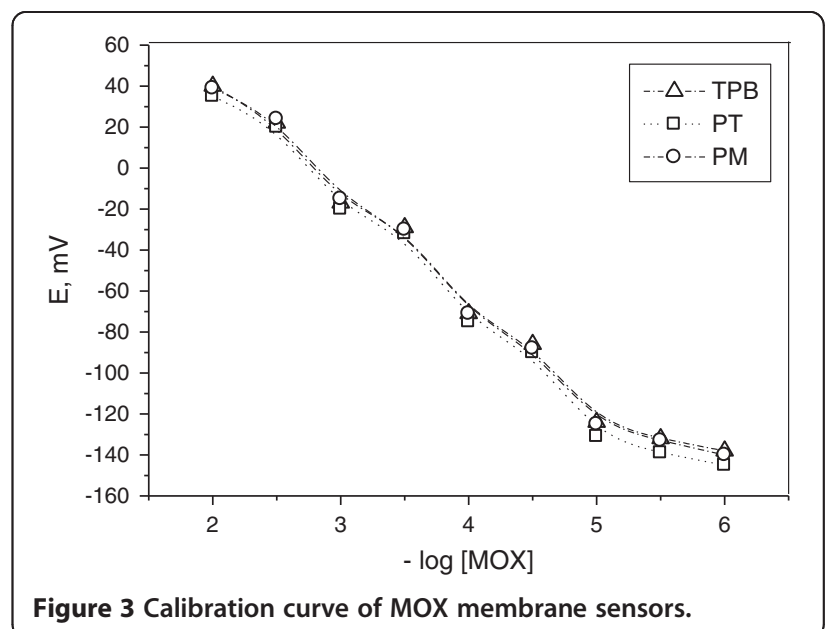


Table 3 Day to day reproducibility of the proposed membrane sensors

\begin{tabular}{|c|c|c|c|c|c|c|}
\hline \multirow[t]{2}{*}{ Parameter } & \multicolumn{3}{|c|}{ Moxifloxacin $(400 \mu \mathrm{g} / \mathrm{ml})^{*}$ within- day } & \multicolumn{3}{|c|}{ Moxifloxacin $(400 \mu \mathrm{g} / \mathrm{ml})^{*}$ within-days } \\
\hline & MOX-TPB & MOX-PM & MOX-PT & MOX-TPB & MOX-PM & MOX-PT \\
\hline $\mathrm{R}, \%$ & 98.5 & 99.1 & 98.60 & 98.3 & 99.0 & 98.5 \\
\hline R.S.D, \% & 1.76 & 1.65 & 1.78 & 1.9 & 1.7 & 1.9 \\
\hline$E, \%$ & 1.52 & 0.9 & 1.41 & 1.72 & 1.0 & 1.52 \\
\hline Slope & $53.0 \pm 0.5$ & $54.5 \pm 0.5$ & $55.0 \pm 0.5$ & $53.0 \pm 0.6$ & $54.5 \pm 0.6$ & $55.0 \pm 0.6$ \\
\hline Correlation coefficient & 0.998 & 0.998 & 0.997 & 0.997 & 0.997 & 0.997 \\
\hline
\end{tabular}

*Average of 5 measurements \pm RSD.

${ }^{*} \mathrm{R} \%$, recovery percentage; RSD relative standard deviation.

${ }^{*} \mathrm{E}$, is error\% ( actual concentration -found concentration/actual concentration\%).

according the IUPAC recommendation [24]. The lower limit of detection (LOD) defined as the concentration of MOX corresponding to the intersection of the extrapolated linear segment of the calibration graph which is of $3 \times 10^{-6}$, $4 \times 10^{-6}$ and $4.0 \times 10^{-6} \mathrm{M}$ for sensor 1,2 and 3 respectively ( Figure 3).

\section{Recovery}

The recoveries of MOX were calculated by comparing the potential of the measured or found concentration to direct added standard in tris buffer $\mathrm{pH}$ 7.0. The assay of recovery, at each concentration, was computed using the following equation:

$$
\begin{aligned}
\operatorname{Recovery}(\%)= & (\text { found concentration/added concentration }) \\
& \times 100 .
\end{aligned}
$$

The average recovery of the direct determinations of $400 \mu \mathrm{g} / \mathrm{ml}$ of MOX was $98.5,99.1$ and $98.6 \%$ with RSD value of $1.76,1.65$ and $1.78 \%$ for sensor 1,2 and 3 respectively (Table 3 ).

\section{Precision and accuracy of the method}

The intra-day, inter-day accuracy and precision of the assays were investigated [27] by the analysis of MOX at $400 \mu \mathrm{g} / \mathrm{ml}$ in five replicate over a period of three days. The five replicate were subject to estimate the intra-day and inter-day precision. Calibration curves were prepared and analyzed daily and linear models were used to determine concentrations in the quality control samples. Percent accuracy was determined (using the data from the precision assessment) as the closeness of found concentration to the added standards. Precision was reported as\% RSD. The results obtained (Table 3) are within the acceptance range of less than $3.0 \%$ (precision) and more than $98.3 \%$ for the accuracy.

\section{Ruggedness}

The ruggedness of the potentiometric method was evaluated [27] by carrying out the analysis using two different analyst (operator) and different instruments on different days. The RSD of less than 3.0\% were observed for repetitive measurements in three different day time periods using two different instruments and operators. The results indicate that the method is capable of producing results with high precision.

\section{Robustness}

The robustness of the method is demonstrated [27] by the versatility of the experimental factors that affecting the potential response (e.g. $\mathrm{pH}$ and response time).

Preliminary inspection of the results under these various conditions suggested that the method is fairly robust, but the $\mathrm{pH}$ of the measuring solution should be in the range of 6.0-9.0. The optimum $\mathrm{pH} 7.0$ was used using tris buffer.

\begin{tabular}{|c|c|c|c|c|c|c|c|c|c|c|c|c|}
\hline \multirow{2}{*}{$\begin{array}{l}\text { Added } \\
(\mu \mathrm{g} / \mathrm{ml})\end{array}$} & \multicolumn{4}{|c|}{ MOX-TPB,* } & \multicolumn{4}{|c|}{ MOX-PM,* } & \multicolumn{4}{|c|}{ MOX-PT, } \\
\hline & $\overline{S D}$ & RSD & $\mathbf{R}$ & $\mathrm{E}$ & $\overline{S D}$ & RSD & $\mathbf{R}$ & $E$ & $\overline{S D}$ & RSD & $\mathbf{R}$ & $E$ \\
\hline 2.0 & 0.0297 & 1.9 & 97.5 & 1.9 & 0.0197 & 1.9 & 98.0 & 1.8 & 0.0220 & 1.9 & 98.0 & 1.95 \\
\hline 4.00 & 0.0297 & 1.9 & 98.1 & 1.8 & 0.0197 & 1.8 & 98.1 & 1.8 & 0.0220 & 1.9 & 98.1 & 1.95 \\
\hline 40.0 & 0.1834 & 1.9 & 98.3 & 1.7 & 0.1761 & 1.7 & 99.1 & 1.74 & 0.229 & 1.8 & 98.4 & 1.64 \\
\hline 400.0 & 2.9664 & 1.7 & 98.2 & 1.2 & 5.000 & 1.6 & 98.2 & 1.74 & 1.378 & 1.8 & 98.6 & 1.24 \\
\hline 1000.0 & 14.1002 & 1.7 & 98.3 & 1.3 & 16.614 & 1.5 & 98.0 & 1.54 & 7.247 & 1.8 & 98.5 & 1.30 \\
\hline 4000.0 & 29.234 & 1.5 & 98.3 & 1.4 & 27.229 & 1.4 & 98.1 & 2.05 & 17.117 & 1.5 & 99.5 & 1.40 \\
\hline
\end{tabular}

Table 4 Direct determinations of moxifloxacin using PVC membrane sensors

SD: standard deviation, RSD: relative standard deviation\%, R: recovery\%, E: error\%.

*Average of 5 measurements. 
Table 5 Determination of moxifloxacin in some pharmaceutical preparations using the proposed membrane sensors

\begin{tabular}{|c|c|c|c|c|c|}
\hline \multirow[t]{2}{*}{ Preparation } & \multirow{2}{*}{$\begin{array}{l}\text { Moxifloxacin } \\
\text { (nominal,value) }\end{array}$} & \multicolumn{3}{|c|}{ Proposed method* R,\% (RSD,\%) } & \multirow{2}{*}{$\begin{array}{l}\text { USP R,\% } \\
\text { (RSD,\%) }\end{array}$} \\
\hline & & MOX-PM & MOX-PT & MOX-PT & \\
\hline Reconstituted powder & $20 \mathrm{mg}$ & $98.0(1.6)$ & $98.0(1.5)$ & $98.5(1.6)$ & $98.5(1.6)$ \\
\hline Avelox tablet & $400 \mathrm{mg}$ & $98.0(1.7)$ & $98.0(1.6)$ & $98.5(1.7)$ & 99.0 ( 1.8) \\
\hline
\end{tabular}

*Average of five determinations.

\section{Determination of MOX in its pharmaceutical preparation} The applicability of the MOX membrane sensors for determination of the drug in the dosage forms was firstly checked by the studying the recovery of an accurate amount of pure MOX in solutions.

The analysis of $2.0-4000.0 \mu \mathrm{g} / \mathrm{ml} \mathrm{MOX} \mathrm{solutions} \mathrm{(in}$ five replicate) by direct potentiometry gave an average recovery of $98.1,98.25$ and $98.51 \%$ with a relative standard deviation of $1.76,1.65$ and $1.78 \%$ for sensor 1,2 and 3 respectively, results are shown in Table 4.

The applicability of the MOX-membrane sensors to the determination of the drug in the dosage forms was firstly checked by studying the recovery of an accurate amount of pure MOX in a reconstituted powder samples. The recovery obtained from five measurements was found to be 98.0 or 98.0 or $98.5 \%$ with a relative standard deviation of 1.7 or 1.6 or $1.7 \%$ for MOX- TPB or MOX-PM or MOX-PT respectively. On the other hand, the determination of MOX in its formulations show an average recovery of 98.0 or 98.5 or $98.5 \%$ with relative standard deviation of 1.7 or 1.6 or $1.7 \%$ for sensor 1 or 2 or 3 , respectively, results are shown in Table 5 .

Results obtained for the analysis of MOX in its formulation by direct measurements using the proposed sensors and the standard USP pharmacopeia method [28] are given in Table 5. The data obtained in Table 5 proves that the potentiometeric method shows a high degree of precision and accuracy compared with US pharmacopoeia method.

\section{Application of MOX-PVC sensors as indictor electrodes}

The developed electrodes in conjunction with an $\mathrm{Ag} / \mathrm{AgCl}$ reference electrode have been examined as an end point indicator electrode for potentiometric titrations of the drug. Titration MOX with sodium tetraphenylborate using MOX-TPB or MOX-PM or MOX-PT sensors has been performed (Figure 4). From the results it is clear that MOX reacts with NaTPB in the molar ratio of $1: 1$. The titration curves were symmetrical with a very well defined potential jump of about $250 \mathrm{mV}$ for MOX-TPB, MOX-PM and MOX-PT respectively, indicating the high sensitivity of the electrodes.

\section{Conclusion}

Three different ion-pair complexes of MOX have been performed as sensors for MOX, the MOX membrane sensor displayed good analytical performance. The sensors display a fast, stable and near-Nernstian response over a relative wide moxifloxacin concentration range $\left(1 \times 10^{-2}-4.0 \times 10^{-6}, 1 \times 10^{-2}-5.0 \times 10^{-6}\right.$, $\left.1 \times 10^{-2}-5.0 \times 10^{-6} \mathrm{M}\right)$ for sensor 1,2 and 3 ,

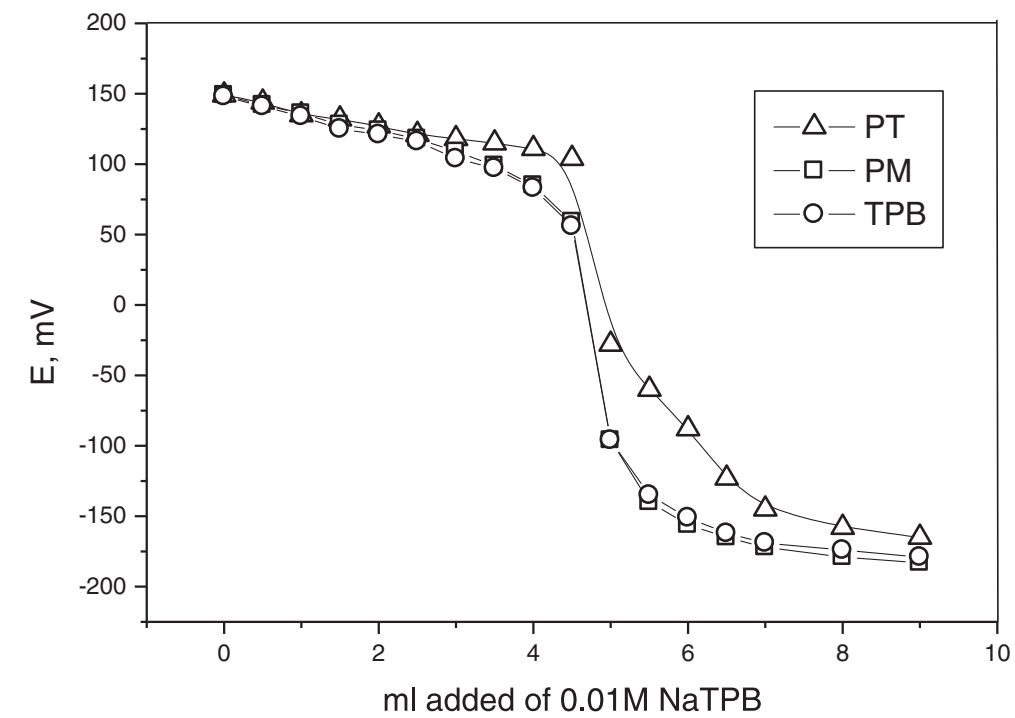

Figure 4 Typical potentiometric titration curves of $5.0 \mathrm{ml}$ of $1 \times 10^{-2} \mathrm{M}$ MOX with $1 \times 10^{-2} \mathrm{M}$ sodium tetraphenylborate using moxifloxacin membrane sensors. 
respectively over a $\mathrm{pH}$ range of 6.0 - 9.0. The direct determination of moxifloxacin show an average recovery of 98.5, 99.1 and $98.6 \%$ and a mean relative standard deviation of $1.8,1.6$ and $1.8 \%$ at $400 \mu \mathrm{g} / \mathrm{ml}$ for sensors 1,2 and 3 respectively. The results obtained are within the acceptance range of less than 3.0\% (precision) and more than $98.3 \%$ for the accuracy. The sensors have been used as indicator electrodes for potentiometric titration of moxifloxacin.

\section{Competing interests}

The authors declare that they have no competing interests.

\section{Authors' contributions}

MMH coordinated the study and modified the text, AMAH conducted the method development, MAA coordinated the study and modified the text, AMA coordinated the study and modified the text, AA coordinated the study and modified the text and GAEM proposed the subject, designed the study, participated in the results discussion and revised the manuscript. All authors read and approved the final manuscript.

\section{Acknowledgements}

The authors extend their appreciation to the Deanship of Scientific Research at King Saud University for funding the work through the research group project No. RGP-VPP-037.

\section{Author details}

'Pharmaceutical Chemistry Department, College of Pharmacy, King Saud University, P.O.Box 2457, Riyadh 11451, Saudi Arabia. ${ }^{2}$ Micro-analytical Lab, National Research Center, Dokki, Cairo, Egypt.

Received: 5 May 2014 Accepted: 3 September 2014

Published online: 17 September 2014

\section{References}

1. Sweetman SC: Martindale: The complete drug reference. 36th edition. Lon: The pharm. press; 2009:302

2. Maryadele JO: The Merck Index: An encyclopedia of chemicals, drugs and biologicals. 14th edition. New Jersey: Merck Research Laboratories, Division of Merck and Co.,Inc. Whitehouse station; 2001:1125.

3. Drlica K, Zhao X: DNA gyrase, topoisomerase IV, and the 4-quinolones. Microbiol Mol Biol Rev 1997, 61(3):PMID 9293187. PMC 232616, 377-92.

4. Motwani SK, Chopra S, Ahmad FJ, Khar RK: Validated spectrophotometric methods for the estimation of moxifloxacin in bulk and pharmaceutical formulations. Spectrochim Acta A 2007, 68:250-6.

5. Elbashir AA, Ebraheem SA, Elwagee AH, Aboul-Enein HY: New spectrophotometric methods for the determination of moxifloxacin in pharmaceutical formulations. Acta Chim Slov 2013, 60:159-65.

6. Kamruzzaman M, Alam AM, Lee SH, Ragupathy D, Kim YH, Park SR, Kim SH: Spectrofluorimetric study of the interaction between europium(III) and moxifloxacin in micellar solution and its analytical application. Spectrochim Acta A 2012, 86:375-80

7. Al-Ghannam SM: Atomic absorption spectroscopic, conductometric and colorimetric methods fordetermination of some fluoroquinolone antibacterials using ammonium reineckate. Spectrochim Acta A 2008, 69:1188-94.

8. Radi AE, Wahdan T, Anwar Z, Mostafa H: Electrochemical determination of gatifloxacin, moxifloxacin and sparfloxacin fluoroquinolonic antibiotics on glassy carbon electrode in pharmaceutical formulations. Drug Test Anal 2010, 2:397-400.

9. $X u Y H, L i D, L i u X Y, L i Y Z, L u$ J: High performance liquid chromatography assay with ultraviolet detection formoxifloxacin: validation and application to a pharmacokinetic study in Chinese volunteers. J Chromatogr B 2010, 878:3437-41.

10. Lemoine T, Breilh D, Ducint D, Dubrez J, Jougon J, Velly JF, Saux MC: Determination of moxifloxacin (BAY 12-8039) in plasma and lung tissue by high-performance liquid chromatography with ultraviolet detection using a fully automated extraction method with a new polymeric cartridge. J Chromatogr B 2000, 742:247-54.
11. Guerra FL, Paim CS, Steppe M, Schapoval EE: Biological assay and liquid chromatographic method for analysis of moxifloxacin in tablets. J AOAC Int 2005, 88:1086-92.

12. Kumar AK, Ramachandran G: Simple and rapid liquid chromatography method for determination of moxifloxacin in plasma. J Chromatogr $B$ 2009, 877:1205-8.

13. Kumar AK, Sudha V, Srinivasan R, Ramachandran G: Simple and rapid liquid chromatography method for determination of moxifloxacin in saliva. J Chromatogr B 2011, 879:3663-7.

14. Goudah A: Pharmacokinetics and tissue residues of moxifloxacin in broiler chickens. Br Poult Sci 2009, 50:251-8.

15. Cruz LA, Hall R: Enantiomeric purity assay of moxifloxacin hydrochloride by capillaryelectrophoresis. J Pharm Biomed Anal 2005, 38:8-13.

16. Möller JG, Stass H, Heinig R, Blaschke G: Capillary electrophoresis with laser-induced fluorescence: a routine method to determine moxifloxacin in human body fluids in very small sample volumes. J Chromatogr $B$ 1998, 716:325-34.

17. Raju B, Ramesh M, Borkar RM, Padiya R, Banerjee SK, Srinivas R: Development and validation of liquid chromatography-mass spectrometric method for simultaneous determination of moxifloxacin and ketorolac in rat plasma: application to pharmacokinetic study. Biomed Chromatogr 2012, 26:1341-7.

18. Pranger AD, Alffenaar JW, Wessels AM, Greijdanus B, Uges DR: Determination of moxifloxacin in human plasma, plasma ultrafiltrate, and cerebrospinal fluid by a rapid and simple liquid chromatography- tandem mass spectrometry method. J Anal Toxicol 2010, 34:135-41.

19. Elzanfaly ES, Zaazaa HE, Merey HA: Ion selective phosphotungestate and beta-cyclodextrin based membraneelectrodes for stability-indicating determination of midodrine hydrochloride. Acta Chim Slov 2013, 60:256-6

20. Hassan SS, Kamel AH, Abd El-Naby H: New potentiometric sensors based on selective recognition sites for determination of ephedrine in some pharmaceuticals and biological fluids. Talanta 2013, 103:330-6.

21. Abu Shawish HM, Khedr AM, Abed-Almonem KI, Gaber M: A comparative study of solid and liquid inner contact benzalkonium chloride ion-selective electrode membranes. Talanta 2012, 101:211-9.

22. Hassan SSM, Marzouk SAM: A novel ferroin membrane sensor for potentiometric determination of iron. Talanta 1994, 41:891-899.

23. Carggs A, Moody GJ, Tomas JDR: PVC matrix membrane ion-selective electrodes. J Chem Educ 1974, 51:541-544.

24. Ma TS, Hassan SSM: Organic Analysis Using Ion Selective Electrodes, Volume 1\&2. London: Academic Press; 1982.

25. Analytical Chemistry Division IUPAC: Recommendation for Nomenclature of Ion Selective Electrode. Pure Appl Chem 1994, 66:2527-2536.

26. Analytical Chemistry Division IUPAC: Potentiometric selectivity coefficients of ion selective electrodes. Pure Appl Chem 2000, 72:1851-2082.

27. Miller JC, Miller JN: Statistics for Analytical Chemistry. 1st edition. England: Ellis Harwood Limited; 1986:p. 43, 53, 59, 189, 192.

28. USP: Non-US Monographs Guideline and is not a USP-NF monograph, moxifloxacin Tablets. The United States Pharmacopeia; 2011. http:/www.usp.org/search/seite/ moxifloxacin\%20tablet.

doi:10.1186/s13065-014-0059-y

Cite this article as: Hefnawy et al.: Potentiometric determination of moxifloxacin in some pharmaceutical formulation using PVC membrane sensors. Chemistry Central Journal 2014 8:59.

\section{Publish with ChemistryCentral and every scientist can read your work free of charge \\ "Open access provides opportunities to our colleagues in other parts of the globe, by allowing anyone to view the content free of charge." \\ W. Jeffery Hurst, The Hershey Company.}

- available free of charge to the entire scientific community

- peer reviewed and published immediately upon acceptance

- cited in PubMed and archived on PubMed Central

- yours - you keep the copyright

Submit your manuscript here:

http://www.chemistrycentral.com/manuscript/<smiles>c1ccccc1</smiles>

Chemistry Central 